This is a PDF file of an unedited manuscript that has been accepted for publication. Final edited form is published in Colloids and Surfaces A, 2013, 435:91-96. http://dx.doi.org/10.1016/j.colsurfa.2013.01.023

\title{
Adsorption of organic acids on magnetite nanoparticles, pH-dependent colloidal stability and salt tolerance
}

\author{
E. Tombácz ${ }^{1 *}$, I. Y.Tóth ${ }^{1}$, D. Nesztor ${ }^{1}$, E. Illés ${ }^{1}$, A. Hajdú ${ }^{1}$, M. Szekeres ${ }^{1 *}$, L.Vékás ${ }^{2}$ \\ ${ }^{1}$ Department of Physical Chemistry and Materials Science, University of Szeged, Hungary \\ ${ }^{2}$ Center of Fundamental and Advanced Technical Research, RA-TD, Timisoara, Romania
}

\section{Corresponding authors}

Etelka Tombácz tombacz@ chem.u-szeged.hu and

Márta Szekeres szekeres@ chem.u-szeged.hu

Address: Department of Physical Chemistry and Materials Science, University of Szeged, Aradi vt. 1, H-6720 Szeged, Hungary.

Phone: +3662544212

Fax: +36 62544042

\section{Graphical abstract}

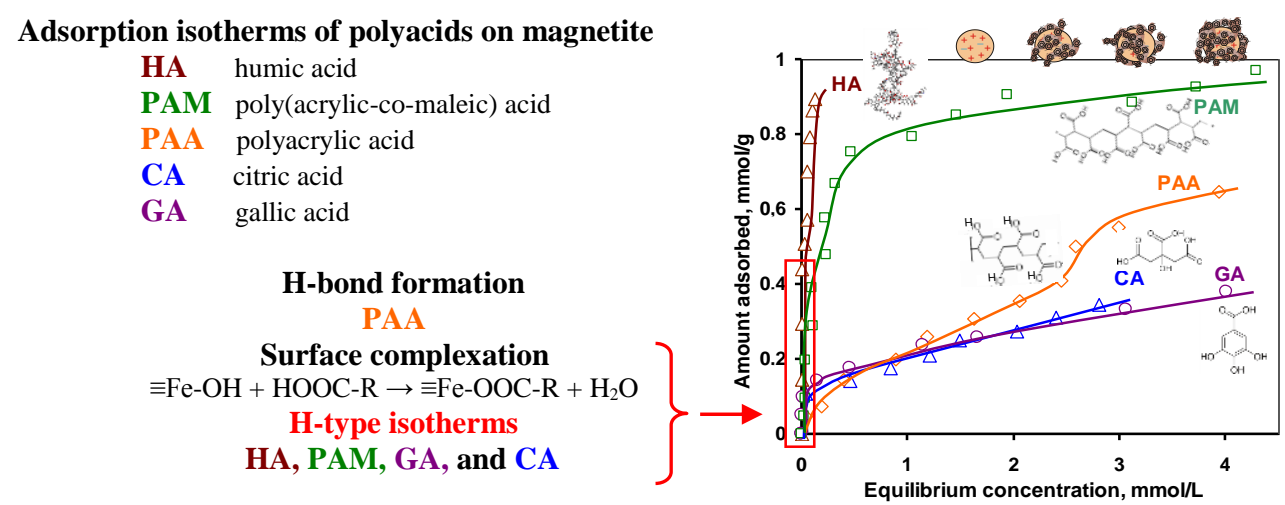

\section{Highlights}

- Organic acids either stabilize or destabilize oxide nanoparticles in natural waters.

- The stabilizing/destabilizing effect depends on $\mathrm{pH}$, salinity and organic concentration.

- Specific configuration of carboxylic groups is necessary to surface complexation.

- Surface complexation leads to high affinity adsorption isotherms.

- Higher molecular weight organic acids provide better stability than smaller ones.
Abstract
The adsorption of different organic acids and their influence on the $\mathrm{pH}$-dependent charging, salt tolerance and so the colloidal stability of magnetite nanoparticles are compared. Adsorption isotherms of citric acid - CA, gallic acid - GA, poly(acrylic acid) - PAA, poly(acrylic-co-maleic acid) - PAM and humic acid - HA were measured. The pH-dependent charge state of MNPs was characterized by electrophoretic mobility and their aggregation by dynamic light scattering. The salt tolerance was tested in coagulation kinetic experiments. Although the adsorption capacities, the type of bonding (either H-bonds or metal ion- carboxylate complexes) and so the bond strengths are significantly different, the following general trends have been found. Small amount of organic acids at $\mathrm{pH}<\sim 8$ (the $\mathrm{pH}$ of PZC of magnetite) - relevant condition in natural waters - only neutralizes the positive charges, and so promotes the aggregation and sedimentation of nanoparticles. Greater amounts of organic acid, above the charge neutralization, cause the sign reversal of particle charge, and at high 
This is a PDF file of an unedited manuscript that has been accepted for publication. Final edited form is published in Colloids and Surfaces A, 2013, 435:91- 96. http://dx.doi.org/10.1016/j.colsurfa.2013.01.023

overcharging promote stabilization and dispersing. The thicker layer of PAA, PAM and HA provides better electrosteric stability than CA and GA. GA undergoes surface polymerization, thereby improving stabilization. The organic acids studied here eliminate completely the $\mathrm{pH}$ sensitivity of amphoteric magnetite, but only the polyanionic coverage provides significant increase in resistance against coagulating effects of salts at neutral $\mathrm{pH}$ commonly prevailing in natural waters.

\section{Keywords:}

Carboxylated magnetite nanoparticles; small and macromolecular organic polyacids; adsorption; nanoparticle stabilization; overcharging;

\section{Introduction}

In aqueous medium, the colloidal stability of dispersed magnetite nanoparticles as an example of environmentally relevant metal oxides depends sensitively on not only the $\mathrm{pH}$, but also the amount of organic acids occurring mainly in surface waters. These organic compounds can modify the surface charge properties of magnetite entirely or partially depending on their chemistry and amounts adsorbed.

The macromolecular humic acids (HA) are an important fraction of the natural organic matter (NOM) [1]. The synthetic polyacrylic acid (PAA) is often studied as HA analogue macromolecular compound. They contain mainly carboxylic acidic groups, similarly to the citric acid (CA). The natural humic macromolecules however, have aromatic rings besides aliphatic parts of carbon skeleton, and so phenolic groups have to be also considered among acidic functions [2]. Gallic acid (GA) is one of the common aromatic compounds having both carboxylic and phenolic groups. It is found frequently in the ester bonds occurring in several natural antioxidants such as flavonoids and green tea, or as a free acid released into the environment. GA is a labile compound, it polycondensates spontaneously under neutral $\mathrm{pH}$ conditions, especially in the presence of mineral particles [3]. HA is able to form appropriate stabilizing layer on metal oxide particles due to its specific affinity to metal ions and polyionic character [4,5]. Besides our several years' experience with aqueous solutions of humic acids, their interaction with magnetite $\left(\mathrm{Fe}_{3} \mathrm{O}_{4}\right.$, magnetic iron oxide) has been also studied $[6,7]$. The CA, PAA and PAM interactions with magnetite nanoparticles have been recently investigated $[8,9,16]$. Besides their environmental relevance, these are important from biomedical application point of view. Although magnetite nanoparticles can be easily prepared by coprecipitation of $\mathrm{Fe}$ (II) and $\mathrm{Fe}$ (III) salts in an alkaline solution, different coating layers on the surface of particles have to be developed to prevent particle aggregation and to improve their colloidal and chemical stability [10]. Surfactants are often used to disperse nanoparticles entirely in an appropriate medium. Coating of single-domain magnetite nanoparticles (typical size of about $10 \mathrm{~nm}$ ) with a double layer of surfactants in an aqueous medium results in stable colloidal dispersions [11]. The coverage of particles with adsorption layer provides enhanced resistance against the particle aggregation. In aqueous medium, electrostatic, steric or combined (i.e., electrosteric) stabilization layers can develop [5,12,13]. The thicker coating provides better stability [14]. Magnetite nanoparticles were stabilized with CA as a well-known complexant of $\equiv \mathrm{Fe}-\mathrm{OH}$ surface sites $[8,15]$, natural polycarboxylic acid $\mathrm{HA}[6,7,8]$ and artificial polymers polyacrylic acid (PAA) and poly(acrylic-co-maleic) acid (PAM) [9,16].

In this work we show how the $\mathrm{pH}$ sensitivity of amphoteric magnetite can be eliminated and a significant increase in the resistance against salt can be reached by coating iron oxide nanoparticles with the above polyanionic acids. The binding of the polyacids to magnetite surface was studied in adsorption experiments and the charging and aggregation of the particles 
This is a PDF file of an unedited manuscript that has been accepted for publication. Final edited form is published in Colloids and Surfaces A, 2013, 435:91-96. http://dx.doi.org/10.1016/j.colsurfa.2013.01.023

in electrokinetic and dynamic light scattering measurements. We compared the effect of the adsorption of the different organic acids on the $\mathrm{pH}$-dependent charging, salt tolerance and so the colloidal stability of magnetite nanoparticles. Some of the results used here can be found in our earlier publications [6-9,16], together with the detailed discussions on the mechanisms of adsorption. Therefore, we do not intend to go into those details, but we use our earlier conclusions to support the findings of the present comparative study on the stabilizing efficiencies of small and large molecular organic acids.

\section{Experimental}

\subsection{Materials}

Synthetic magnetite $\left(\mathrm{Fe}_{3} \mathrm{O}_{4}\right)$ was prepared by alkaline hydrolysis of iron (II)- and iron (III)-salts. The method was used to prepare superparamagnetic magnetite with particle size below $10 \mathrm{~nm}$. The details of preparation and the characterization of magnetite itself can be found in the papers published before $[7,17,18,19]$.

Reagent grade citric acid (CA) and gallic acid (GA), and the polyelectrolytes polyacrylic acid (PAA, $\mathrm{M}_{\mathrm{w}}=1800$ DA) and poly(acrylic-co-maleic) acid (PAM, $\mathrm{M}_{\mathrm{w}}=3000 \mathrm{DA}, 50 \mathrm{wt}$ \% in $\mathrm{H}_{2} \mathrm{O}$ ) were purchased from Sigma-Aldrich.

Humic acid (HA) was obtained from brown coal (Tatabánya, Hungary) by a traditional alkaline extraction procedure using $0.1 \mathrm{M} \mathrm{NaOH}$ solution. The ash content of raw HA was reduced by $\mathrm{HF} / \mathrm{HCl}$ treatment below $1 \%$. The dried, ground $\mathrm{HA}$ was extracted with benzene/ethanol in a Soxhlet apparatus for 72 hours to remove tar components. Na-humate solution was prepared from the dried HA sample dissolved it in a calculated amount of $\mathrm{NaOH}$ to be equivalent to the total acidity of HA measured by potentiometric titration [6]. The amount of humic acids in moles cannot be given, because the molecular weight of these natural materials is undefined due to their polydisperse and fractal nature [1]. Because mainly the acidic functional groups (carboxyl and phenolic $\mathrm{OH}$ ) take part in the complexation reactions and adsorption processes, it is straightforward to express the amount of HA in relation to the amount of these groups. The whole amount of the acidic groups related to the unit mass of HA (i.e., the total acidity of the sample) was $3.5 \mathrm{mmol} / \mathrm{g}$, which was used to give the concentration of HA solutions in $\mathrm{mmol} / \mathrm{L}$ unit. The amount of the other two polyelectrolytes PAA and PAM $\left(\mathrm{M}_{\mathrm{w}} \sim\right.$ $3000 \mathrm{Da}$ for both) was related to the number of carboxylic groups in the monomer units: $\mathrm{COOH} / \mathrm{AA}=1$ and $-\mathrm{COOH} / \mathrm{AM}=3$. The molar weights of the monomers are $72(\mathrm{AA})$ and 188 (AM) $\mathrm{g} / \mathrm{mol}$. We did not use the amount of carboxylic groups to express concentration in the case of small molecules (CA and GA), because their molecular weight is exact and it allows to get a clear molecular picture of the interactions.

$\mathrm{NaCl}, \mathrm{HCl}$ and $\mathrm{NaOH}$, used to set the $\mathrm{pH}$ and ionic strength, were analytical grade products of Reanal (Hungary). Milli-Q water was used. All experiments were performed at room temperature $\left(25 \pm 1{ }^{\circ} \mathrm{C}\right)$.

\subsection{Methods}

\subsubsection{Adsorption}

The adsorption isotherms of the polyacids at $\mathrm{pH} \sim 6$ and constant salt concentration of $0.01 \mathrm{M} \mathrm{NaCl}$ were determined by batch method. The magnetite suspensions $(1 \mathrm{~g} / \mathrm{L})$ were equilibrated with the series of polyacid solutions up to $10 \mathrm{mmol} / \mathrm{L}$ concentration in closed test tubes for $24 \mathrm{~h}$ at room temperature. The $\mathrm{pH}$ was adjusted to $6.5 \pm 0.1$ by adding small portions of either $\mathrm{NaOH}$ or $\mathrm{HCl}$ solutions and checked after adsorption time for $24 \mathrm{~h}$. The equilibrium 
This is a PDF file of an unedited manuscript that has been accepted for publication. Final edited form is published in Colloids and Surfaces A, 2013, 435:91- 96. http://dx.doi.org/10.1016/j.colsurfa.2013.01.023

concentrations were determined by measuring the absorbance of supernatants at $260 \mathrm{~nm}(\mathrm{GA})$, $450 \mathrm{~nm}$ (HA) or the differential absorbance at 223 and $250 \mathrm{~nm}$ (PAA and PAM) in an USB4000 spectrometer (Ocean Optics) after perfect separation of the solid particles by centrifuging at 13000 RPM for 1 hour. At higher polyacid concentrations the separation was assisted by a permanent magnet and membrane filtration $(0.22 \mu \mathrm{m}$ MILLEX-GP). The equilibrium concentration of CA was determined by cerimetric titration using ferroin indicator [15].

\subsubsection{Electrophoretic mobility measurement}

Electrophoretic mobilities of the pure (naked) and the polyacid coated magnetite samples were measured at $25 \pm 0.1^{\circ} \mathrm{C}$ in a disposable zeta cell (DTS 1060) of NanoZS (Malvern, UK) apparatus. The settings of the instrument were checked by measuring a standard latex sample with the zeta potential of $\sim 55 \pm 5 \mathrm{mV}$. The measurements were performed under optimal scattering condition ( $\sim 10^{5}$ counts per seconds) applying either 0.05 or $0.1 \mathrm{~g} / \mathrm{L}$ magnetite content depending on the aggregation state of the dispersions. The range of $\mathrm{pH}$ was between $\sim 3$ and $\sim 10$. The measurements were started after one hour equilibration time. In one series of experiments the effect of the added amounts of polyacids (expressed as the amounts of acidic groups for HA, PAA and PAM) up to $0.6 \mathrm{mmol}$ related to $1 \mathrm{~g}$ magnetite was measured at $\mathrm{pH} \sim 6$. Then, the $\mathrm{pH}$-dependence was investigated in the presence of various selected amounts of polyacids ranging from 0.05 to $1.8 \mathrm{mmol} / \mathrm{g}$. The experiments were performed at constant ionic strengths $0.005 \mathrm{M}(\mathrm{CA}), 0.002 \mathrm{M}(\mathrm{HA})$ and $0.01 \mathrm{M}$ (GA, PAA and PAM) set by $\mathrm{NaCl}$.

\subsubsection{Particle sizing - dynamic light scattering (DLS)}

Measurements were performed using a NanoZS apparatus (Malvern, UK) with a $\mathrm{He}-\mathrm{Ne}$ laser $(\lambda=633 \mathrm{~nm})$, operating in backscattering mode at angle $173^{\circ}$. The stock sol of magnetite particles was diluted with $\mathrm{NaCl}$ electrolyte to achieve $0.1 \mathrm{~g} / \mathrm{L}$ solid content. The $\mathrm{pH}$ of the systems was adjusted in the range of 3 to 10 , measured directly before placing the sample in the measuring cell. The $\mathrm{pH}$-dependent particle aggregation was measured at constant ionic strength, $0.005 \mathrm{M}(\mathrm{CA}), 0.002 \mathrm{M}$ (HA) and $0.01 \mathrm{M}$ (GA, PAA and PAM), set by $\mathrm{NaCl}$. The stabilizing effect of the adsorption of polyacids was investigated at different added amounts of them similarly to that in the electrophoretic mobility measurements. All measurements were performed at a given kinetic state achieved by $10 \mathrm{~s}$ of ultrasonication followed by $110 \mathrm{~s}$ of relaxation. The average values of the hydrodynamic diameter were calculated from 3rd order cumulant fits of the correlation functions.

\subsubsection{Coagulation kinetic measurement}

The salt tolerance of stabilized magnetite nanoparticles was tested in coagulation kinetic measurements by using Zetasizer 4 (Malvern, UK) apparatus. $\mathrm{NaCl}$ concentration was changed gradually from $0 \mathrm{mM}$ to $1000 \mathrm{mM}$ at $\mathrm{pH} \sim 6$. The magnetite sol concentration to achieve optimum scattering and diffusion conditions was $0.0025 \mathrm{~g} / \mathrm{L}$. The DLS method was used to follow the size evolution of aggregates in time. The coagulation rate was calculated from the slope of kinetic curves as explained before $[7,12]$. The stability ratio (W) was calculated from the initial slopes of kinetic curves belonging to the slow and fast coagulation as suggested in literature $[20,21]$. To ensure the onset of fast coagulation regime, at least three different, instantly coagulating concentrations of $\mathrm{NaCl}$ were applied. The critical coagulation concentration (CCC) was determined from the $\log _{10} \mathrm{~W}$ versus $\log _{10} \mathrm{C}_{\mathrm{NaCl}}(\mathrm{NaCl}$ concentration) function. In a typical experiment, changes in the hydrodynamic diameter (Z-average values, $Z_{\text {ave }}$ ) were monitored for an hour with a time resolution of 2 minutes. 
This is a PDF file of an unedited manuscript that has been accepted for publication. Final edited form is published in Colloids and Surfaces A, 2013, 435:91-96. http://dx.doi.org/10.1016/j.colsurfa.2013.01.023

\section{Results and Discussion}

\subsection{Adsorption of carboxylic acids on magnetite nanoparticles}

The adsorption isotherms of the different low and high molecular weight carboxylic acids are seen in Fig. 1. The adsorbed amounts represent mmoles of CA or GA per g of MNP, and mmoles of $-\mathrm{COOH}$ groups per $\mathrm{g}$ of MNP for the polyelectrolytes, and thus only the feature of the isotherms is directly comparable. All the isotherms, with the exception of PAA, are of H-type, meaning that the adsorption is of high affinity. This is explained [22] by either the cooperative interactions occurring between the many functional groups of the macromolecules and the surface sites of the MNPs or the intrinsic high affinity of the individual carboxyl groups to the surface sites. We have proven the formation of direct metal-carboxylate surface complexes in the case of CA, PAM and HA $[6,8,15,16]$, and only H-bonding in the case of PAA [9]. The results suggest that surface Fe-carboxylate complex bonds can form when the geometric arrangement of the neighboring carboxyl groups matches the distance between surface $\equiv \mathrm{Fe}-\mathrm{OH}$ sites. We have found that carboxylic groups belonging to neighboring carbon atoms in CA and in the carbon backbone of PAM and HA can take part in such interaction. The neighboring carboxylates in PAA belong to every second $\mathrm{C}$ atom of the backbone of polyacid chain, a geometrically unfavorable condition for Fe-carboxylate formation.

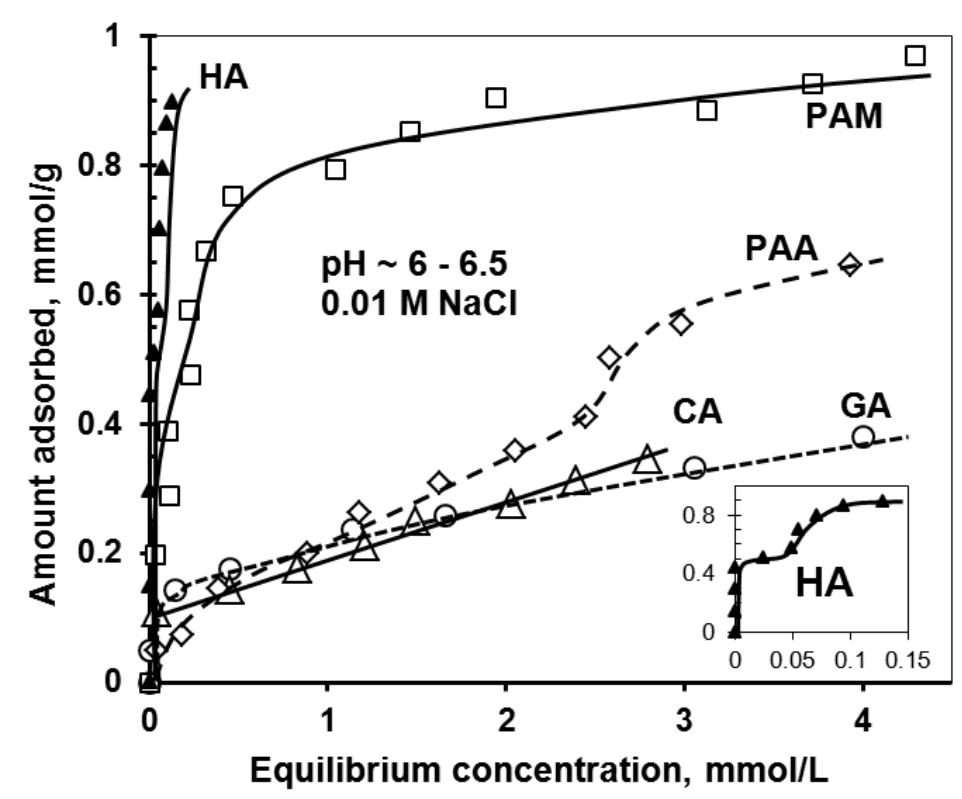

Fig. 1. Adsorption isotherms of carboxylic acids on magnetite nanoparticles measured at $\mathrm{pH} \sim 6-$ 6.5 and 0.01 $\mathrm{M}$ ionic strength. The enlargement of the HA isotherm is seen in the inset. (The amount of the macromolecular polyacids (HA, PAA and PAM) was related to the moles of acidic groups. The lines are drawn to guide the eyes.)

In the case of GA, the high adsorption affinity can result from $\pi$-electron interactions with the polar surface of the MNPs, as well as from complex bond formation at $\equiv \mathrm{Fe}-\mathrm{OH}$ sites with the participation of two neighboring phenolic $\mathrm{OH}$ groups of GA [23]. It should be noted that although the shape of the PAA, CA and GA isotherms may look somewhat similar at low equilibrium concentrations, the high-affinity part is definitely absent from the PAA isotherm. The latter is a clear indication that the mechanism of PAA adsorption is different from that of 
This is a PDF file of an unedited manuscript that has been accepted for publication. Final edited form is published in Colloids and Surfaces A, 2013, 435:91- 96. http://dx.doi.org/10.1016/j.colsurfa.2013.01.023

$\mathrm{CA}$ and GA. The adsorption of PAA, PAM and HA reaches definite plateau region at the adsorbed amounts of $\sim 0.6$ [9], $\sim 0.9$ [16] and $\sim 0.85 \mathrm{mmol} / \mathrm{g}$, respectively. The full isotherms of PAA and PAM adsorption (up to their equilibrium concentration of $\sim 8$ and $\sim 7 \mathrm{mmol} / \mathrm{L}$, respectively) are seen in [9] and [16]. On the contrary, once the high-affinity adsorption limit $(\sim 0.1 \mathrm{mmol} / \mathrm{g})$ has been exceeded, the adsorption of both CA and GA increases linearly without leveling off at a plateau value. The linear increase in the adsorbed amounts is probably connected with the polymerization of the molecules in the adsorption layer. It is well known that GA polymerizes easily in solution [24]. After its adsorption, the polymerization continues with an even greater rate at the surface as well [3]. Regarding the linear part of the CA isotherm, our preliminary studies clearly indicate the appearance of $\mathrm{C}=\mathrm{O}$ vibrations in the FTIR spectra belonging to ester groups; the results being published in a forthcoming paper on the adsorption mechanism of CA and GA.

\subsection{The effect of different organic acids on particle charge of magnetite}

The addition of carboxylic acids to the MNP dispersions at $\mathrm{pH} \sim 6.5$ and $\mathrm{I}=0.01 \mathrm{M}$ had a pronounced effect on the electrokinetic potential of the particles, as seen in Fig. 2. During the adsorption, the polyacids CA, HA, PAM and PAA take negative charges to the surface in excess of that necessary to neutralize the original positive charges of the magnetite at the given $\mathrm{pH}$ and ionic strength. The amount of carboxylic acids at the point of charge neutralization (the zero value of the electrokinetic potential, a kind of isoelectric point - IEP) is nearly the same for all the four macromolecular polyacids; the small deviations are within the inaccuracy range of the measurements $( \pm 5 \mathrm{mV}$, Experimental section, 2.2.2. Electrophoretic mobility measurement). According to our conception, these amounts are the actual moles of $-\mathrm{COO}^{-}$ groups linking the polyacids to the surface sites. Further adsorption of the polyions in excess of surface charge neutralization causes charge reversal of particles. Addition of GA, a monocarboxylic acid, should not induce charge reversal, if the carboxylic group becomes coordinated or electrostatically attached to the surface. The changes in the electrokinetic potential of MNPs with increasing GA adsorption are very similar to that of the polyacids, meaning that GA adsorption neutralizes and

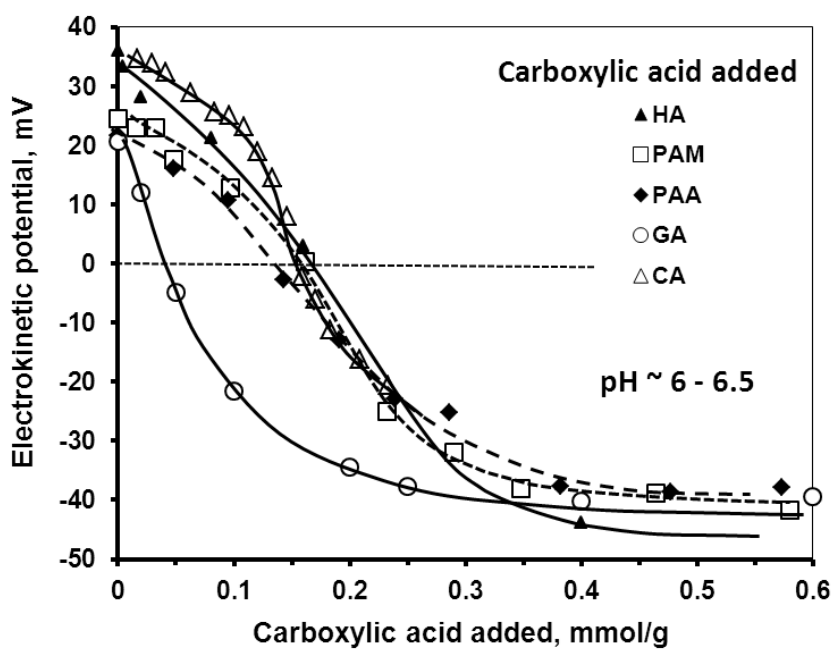

Fig. 2. Effect of the addition of carboxylic acids on the electrokinetic potential of the MNPs, measured at $\mathrm{pH} \sim 6-6.5$, and at $\mathrm{I}=0.01 \mathrm{M}$. (The amount of the macromolecular polyacids (HA, 
PAA and PAM) was related to the moles of their acidic groups. The lines are drawn to guide the eyes.)

overcharges the MNPs. This single fact shows that the carboxylic groups of GA are not involved directly in GA bonding to MNPs, which is in line with the findings in Ref. [23]. The electrokinetic potential of the GA-coated MNPs changes with time, as it is presented in Fig. 3. This unique behavior indicates that surface polymerization of GA proceeds, leading to the increasing thickness of the coating shell and the decreasing absolute values of electrokinetic potential. We will give a detailed analysis of the adsorption, surface polymerization and stabilizing effect of GA on MNPs in a forthcoming publication.

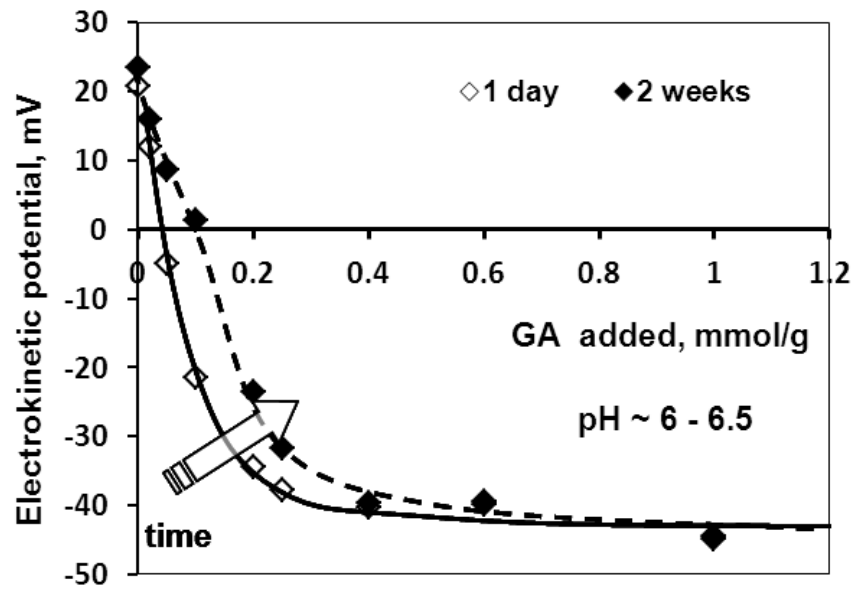

Fig.3. Time-dependence of the electrokinetic potential of GA-coated MNPs. (The lines are drawn to guide the eyes.)

We have also studied the stability of the dispersions in the function of the added amount of the carboxylic acids by measuring the size of the primary particles and aggregates in DLS experiments. The results show that MNPs aggregate at $\mathrm{pH} \sim 6.5$ and $0.01 \mathrm{M}$ ionic strength and the hydrodynamic diameter of the aggregates is $\sim 300 \mathrm{~nm}$. The size of the aggregates increases with addition of small amounts $(0.1-0.2 \mathrm{mmol} / \mathrm{g})$ of carboxylic acids up to $\mathrm{d} \sim 1000$ or even to $\sim 2000 \mathrm{~nm}$. Larger amounts of each polyacid decrease the hydrodynamic diameter down to the size of the primary MNPs (around $100 \mathrm{~nm}$ ) measured for the uncoated particles at $\mathrm{pH}<5$, well below the IEP of naked MNPs ( $\mathrm{pH}>8$ [8]). Thus, all carboxylated coatings can stabilize the individual MNPs at the most common $\mathrm{pHs}$ generally prevailing in environmental waters.

\subsection{The effect of small and macromolecular organic acid coating on the pH-dependent charge state and aggregation of magnetite}

We have examined the stabilizing effect of the different carboxylic acids in terms of the breadth of the $\mathrm{pH}$ range, in which the coated nanoparticles are dispersed individually in a colloidally stable state. As it is seen on the left side in Fig. 4, the IEP of MNPs shifts from $\mathrm{pH} \sim 8$ to lower $\mathrm{pH}$ values upon addition of $0.1 \mathrm{mmol} / \mathrm{g}$ of all carboxylic acids. At their higher added amounts $(1.2-1.8 \mathrm{mmol} / \mathrm{g}$, right side in Fig. 4$)$ the electrokinetic charge of the coated particles was principally negative in the whole range of $\mathrm{pH}$ studied here. In the presence of the small molecules CA and GA, the IEP shifted to $\mathrm{pH} \sim 3$, and so the $\mathrm{pH}$-range of their stability is narrower than that of the polyacids. The size of the particles (individual and aggregated) was measured in DLS experiments in parallel with the electrokinetic potential measurements, to support that aggregation occurs near the IEPs. 
This is a PDF file of an unedited manuscript that has been accepted for publication. Final edited form is published in Colloids and Surfaces A, 2013, 435:91- 96. http://dx.doi.org/10.1016/j.colsurfa.2013.01.023
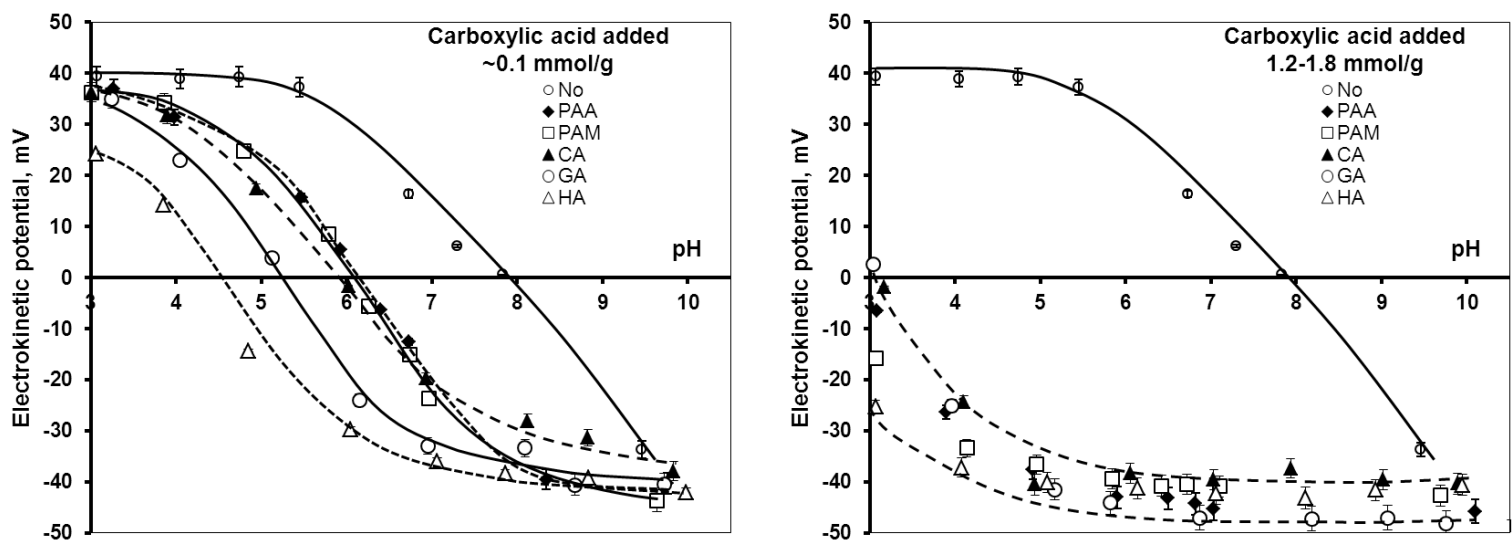

Fig. 4. Shifting in the values of the electrokinetic potential of the MNPs due to the addition of small (left side) and large (right side) amounts of carboxylic acids, measured at different $\mathrm{pHs}$ and at $\mathrm{I}=0.01 \mathrm{M}$. (The lines are drawn to guide the eyes.)

The $\mathrm{pH}$-ranges of aggregation are shown in Table 1 together with the IEP values. The results show that the $\mathrm{pH}$-dependent stability shifts in parallel with IEP in each case, the differences are only in the amounts that can completely mask the original amphoteric feature of magnetite. In addition, small deviation in the average hydrodynamic sizes of particles covered by different organic acids has been found due to the difference in the structure and thickness of the adsorbed layers. High molecular weight polyelectrolytes generally led to larger values of hydrodynamic diameter than smaller molecules, for example, $\sim 150 \mathrm{~nm}$ for PAA and PAM [16, 19], as compared to $\sim 100 \mathrm{~nm}$ for CA and GA stabilized systems, measured in dynamic light scattering experiments.

Table 1. Effect of the quality and added amounts of carboxylic acids on the IEP and the pHrange of aggregation of MNPs

\begin{tabular}{|c|c|c|c|}
\hline $\begin{array}{c}\text { Carboxylated } \\
\text { coating agents }\end{array}$ & $\begin{array}{c}\text { Added amount* } \\
\mathrm{mmol} / \mathrm{g}\end{array}$ & $\begin{array}{c}\mathrm{pH} \text { of } \\
\text { IEP }\end{array}$ & $\begin{array}{c}\text { pH-range of } \\
\text { aggregation }\end{array}$ \\
\hline \multirow{3}{*}{$\mathrm{CA}$} & 0.13 & 6.0 & $4.5-9.5$ \\
\cline { 2 - 4 } & 0.65 & 3.0 & $<4.5$ \\
\hline \multirow{4}{*}{ GA } & 0.02 & 6.8 & $<9$ \\
\cline { 2 - 4 } & 0.1 & 4.8 & $<7.5$ \\
\cline { 2 - 4 } & 0.6 & 4.2 & $<6$ \\
\hline \multirow{3}{*}{ PAA } & 1.8 & 2.7 & $<5.2$ \\
\cline { 2 - 4 } & 0.1 & 6.5 & $4-7$ \\
\cline { 2 - 4 } & 0.48 & 3.8 & $3.5-5.5$ \\
\hline \multirow{3}{*}{ PAM } & 1.15 & 3.0 & $<3.5$ \\
\cline { 2 - 4 } & 0.1 & 6.2 & $3.5-8.5$ \\
\cline { 2 - 4 } & 0.47 & 3.5 & $<5$ \\
\hline \multirow{2}{*}{ HA } & 1.3 & 2.5 & $<3.5$ \\
\cline { 2 - 4 } & 0.08 & 4.3 & $3.5-8.5$ \\
\hline
\end{tabular}

* The added amount of HA, PAA and PAM was related to the moles of their acidic groups. 
This is a PDF file of an unedited manuscript that has been accepted for publication. Final edited form is published in Colloids and Surfaces A, 2013, 435:91-96. http://dx.doi.org/10.1016/j.colsurfa.2013.01.023

\subsection{Salt tolerance of different carboxylated magnetite nanoparticles}

Salt tolerance of the MNPs coated with different amounts of carboxylic acids was measured at $\mathrm{pH} 6.5$ in coagulation kinetics experiments. We observed that the critical coagulation concentration (CCC) of the coagulating $\mathrm{NaCl}$ electrolyte increases with increasing amount of carboxylic acid, if the IEP of the actual carboxylic acid coated MNP is lower than $\mathrm{pH} \sim 6.5$. In the case that the added amount of carboxylic acids is insufficient to decrease IEP well below $\mathrm{pH}$ 6.5, the CCC does not increase compared to that of the naked MNPs. At low coverage, the partially covered (i.e., decorated) particles can aggregate because of the electrostatic attraction between the oppositely charged uncoated and coated patches on the particle surfaces $[7,25]$. The highest attained values of CCC and the respective amounts of added polyacids are collected in Table 2. It is seen that the small molecules CA and GA cannot stabilize the MNPs at neutral $\mathrm{pH}$ to resist higher salt concentrations, despite the approximately identical values of electrokinetic potentials (within the range of -35 to $-55 \mathrm{mV}$ at $\mathrm{pH} \sim 6.5$, right side of Fig. 4). On the contrary, the thicker coating shells prepared with macromolecular polyelectrolytes PAA, PAM, HA and the surface polymerized PGA enhance the salt resistance equally up to $\mathrm{CCC} \sim 500 \mathrm{mM}$.

It is worth mentioning that there are hardly any publications giving $\mathrm{CCC}$ values for colloidal particles, relevant for the magnetite/polyelectrolyte systems studied here. In the paper of J.-D. Hu and co-workers [26] the CCC value of magnetite nanoparticles is given in the presence of $20 \mathrm{mg} / \mathrm{g}$ of humic acid at $\mathrm{pH}=9.8$ as $125.5 \mathrm{mM}(\mathrm{NaCl})$. At this high $\mathrm{pH}$, the magnetite itself had considerable electrostatic stability with $\mathrm{CCC}=23.8 \mathrm{mM} \mathrm{NaCl}$ (for comparison, $\mathrm{CCC}=1 \mathrm{mM} \mathrm{NaCl}$

at $\mathrm{pH} \sim 6.5$ in our experiments) and the charge of both MNPs and HA is negative. Correspondingly, the adsorbed amount of the humate must be low, i.e., restricted to the specific effects only (e.g., Fe-carboxylate surface complex formation), which are

Table 2. CCC values of uncoated and polyacid coated MNPs, measured at $\mathrm{pH} \sim 6.5$.

\begin{tabular}{|c|c|c|}
\hline Polyacids@MNP & $\begin{array}{c}\text { Added amount* } \\
\text { mmol/g }\end{array}$ & $\begin{array}{c}\text { Approx. CCC } \\
\mathrm{NaCl}, \mathrm{mM}\end{array}$ \\
\hline Naked MNP & 0 & 1 \\
\hline CA@MNP & 0.3 & 70 \\
\hline GA@MNP & 2 & $20^{* *}$ \\
\hline PAA@MNP & 1.12 & 500 \\
\hline PAM@MNP & 1.18 & 500 \\
\hline HA@MNP & 1.5 & 500 \\
\hline PGA@MNP & 2 & $500^{* * *}$ \\
\hline
\end{tabular}

* The added amount of HA, PAA and PAM was related to the moles of their acidic groups.

** measured after 1 hour standing

*** measured after 2 weeks standing (while GA surface polymerization took place)

hardly affected by $\mathrm{pH}$. Of course, the probability of close contact of HA carboxylates and $\equiv \mathrm{Fe}-$ $\mathrm{OH}$ groups on MNP surface, thus the chance of complex formation, is reduced by the increased electrostatic repulsion at $\mathrm{pH}=9.8$. Unfortunately, the authors did not provide adsorption data. Nevertheless, even under electrostatically unfavorable conditions, the stabilizing effect of HA on MNPs has been shown. 
This is a PDF file of an unedited manuscript that has been accepted for publication. Final edited form is published in Colloids and Surfaces A, 2013, 435:91-96. http://dx.doi.org/10.1016/j.colsurfa.2013.01.023

\section{Conclusion}

The colloidal stability of magnetite as an example among the environmentally relevant iron oxides dispersed in aqueous medium depends sensitively on not only the $\mathrm{pH}$, but also the amount of organic acids such as humic acids occurring mainly in surface waters. These polyanionic organic complexants can modify the surface charge properties of magnetite entirely or in a certain degree depending on their amount adsorbed.

The adsorption of different organic acids and its effects on the $\mathrm{pH}$-dependent colloidal stability and salt tolerance of magnetite nanoparticles were studied. The adsorbed amounts were given in the molar amount of acidic groups per unit mass of iron oxide for macromolecular acids HA, PAA, PAM and PGA. This approach made the quantitative comparison of the amounts of acidic groups of large organic acids (both the well, and the undefined polyelectrolytes) in the adsorbed layer with the amount of surface charge of magnetite practicable. Thus, the charge neutralization and charge reversal could be interpreted on chemical bases. The specific chemical feature of the interacting partners has to be considered, because chemical reactions take place at the electrified interface, i.e., the functional groups of organic acids interact with the charged/uncharged surface sites of magnetite. The exact feature of the specific interactions depends definitely on the geometry of complexing groups of organic molecules.

Trace amounts of the organic acids can destabilize magnetite dispersions, while their high loading masks the original surface properties of magnetite and improves colloidal stability and salt tolerance of dispersions. Trace amounts of CA, GA, PAA, PAM or HA only neutralize the positive charges of magnetite at $\mathrm{pH}$ lower than its $\mathrm{pH} \mathrm{PZC} \sim 8$, and so promote aggregation between the particles having both positive surface sites and negative patches coated by the organic polyanions. These conditions, i.e., fine iron oxide particles dispersed in water with neutral or slightly acidic $\mathrm{pH}$ and only trace amount of organic acids dissolved in it, are relevant in natural waters. In the presence of greater amounts of polyacids (above the adsorption saturation) however, the surface coverage of magnetite becomes completed causing a sign reversal of particle charge and overcharging of nanoparticles. The thicker layer of the macromolecular coating shell provides better electrosteric stability than that formed from the small molecules of CA or GA. It has been proved that the $\mathrm{pH}$ sensitivity of amphoteric magnetite can be completely eliminated by both small and large molecular stabilizers, but only the macromolecular coverage of particles increases significantly in the resistance against salt at neutral $\mathrm{pH}$ commonly prevailing in natural waters. One additional interesting finding is that apparently there is no correlation between the stabilizing efficiency of the carboxylic acids and the concentration of the fully dissociated carboxylic groups.

Acknowledgement: This work was supported by OTKA (NK 84014) foundation. The financial support by the TÁMOP-4.2.2/B-10/1-2010-0012 fund is gratefully appreciated.

\section{References}

[1] E. Tombácz, Colloidal properties of humic acids and spontaneous changes of their colloidal state under variable solution conditions, Soil Sci. 164 (1999) 814-824.

[2] E. Tombácz, Effect of environmental relevant organic complexants on the surface charge and the interaction of clay mineral and metal oxide particles, in: S. Barany (Eds.), Role of Interfaces in Environmental Protection, Kluver Academic Publishers, Netherlands, 2003, pp. 397-424.

[3] E. Tombácz, M. Szekeres, L. Baranyi, E. Micheli, Surface modification of clay minerals by organic polyions, Colloids Surf., A 141 (1998) 379-384. 
This is a PDF file of an unedited manuscript that has been accepted for publication. Final edited form is published in Colloids and Surfaces A, 2013, 435:91-96. http://dx.doi.org/10.1016/j.colsurfa.2013.01.023

[4] L. Weng, W.H. Van Riemsdijk, L.K. Koopal, T. Hiemstra, Adsorption of humic substances on goethite: comparison between humic acids and fulvic acids, Environ. Sci. Technol. 40 (2006) 7494-7500.

[5] L. Weng, W.H. Van Riemsdijk, T. Hiemstra, Adsorption of humic acids onto goethite: effects of molar mass, pH and ionic strength, J. Colloid Interface Sci. 314 (2007) 107-118. [6] E. Illés, E. Tombácz, The role of variable surface charge and surface complexation in the adsorption of humic acid on magnetite, Colloids Surf., A 230 (2004) 99-109.

[7] E. Illés, E. Tombácz, The effect of humic acid adsorption on pH-dependent surface charging and aggregation of magnetite nanoparticles, J. Colloid Interface Sci. 295 (2006) 115123.

[8] A. Hajdú, E. Illés, E. Tombácz, I. Borbáth: Surface charging, polyanionic coating and colloid stability of magnetite nanoparticles, Colloids Surf., A 347 (2009) 104-108.

[9] A. Hajdú, M. Szekeres, I.Y. Tóth, R.A. Bauer, J. Mihály, I. Zupkó, E. Tombácz, Enhanced stability of polyacrylate-coated magnetite nanoparticles in biorelevant media, Colloids Surf., B 94 (2012) 242-249.

[10] S.C. Pang, S.F. Chin, M.A. Anderson, Redox equilibria of iron oxides in aqueousbased magnetite dispersions: effect of $\mathrm{pH}$ and redox potential, J. Colloid Interface Sci. 311 (2007) 94-101.

[11] C. Scherer, A.M. Figueiredo Neto, Ferrofluids: properties and applications, Braz. J. Phys. 35 (2005) 718-727.

[12] R.J. Hunter, Foundations of Colloid Science, vol. I, Clarendon Press, Oxford, 1987.

[13] M.M. Ramos-Tejada, A. Ontiveros, J.L. Viota, J.D.G. Durán, Interfacial and rheological properties of humic acid/hematite suspensions, J. Colloid Interface Sci. 268 (2003) 85-95.

[14] S. Odenbach, Ferrofluids-magnetically controlled suspensions, Colloids Surf., A 217 (2003) 171-178.

[15] A. Hajdú, E. Tombácz, E. Illés, D. Bica, L. Vékás, Magnetite nanoparticles stabilized under physiological conditions for biomedical application, Prog. Colloid Polym. Sci. 135 (2008) 29-37.

[16] I.Y. Tóth, R.A. Bauer, D. Nesztor, M. Szekeres, E. Tombácz, Designed polyelectrolyte shell on magnetite nanocore for dilution-resistant biocompatible magnetic fluids, Langmuir 28 (2012), 16638-16646.

[17] L. Vékás, D. Bica, O. Marinica, Magnetic nanofluids stabilized with various chain length surfactants, Rom. Repts. Phys. 58 (2006) 217-228.

[18] D. Bica, L. Vékás, M.V. Avdeev, O. Marinica, V. Socoliuc, M. Balasoiu, V.M. Garamus, Sterically stabilized water based magnetic fluids: synthesis, structure and properties, J. Magn. Magn. Mater. 311 (2007) 17-21.

[19] E. Tombácz, E. Illés, A. Majzik, A. Hajdú, N. Rideg, M. Szekeres, Ageing in the inorganic nanoworld: example of magnetite nanoparticles in aqueousmedium, Croatica Chem. Acta 80 (2007) 503-515.

[20] M. Schudel, S.H. Behrens, H. Holthoff, R. Kretzschmar, M. Borkovec, Absolute aggregation rate constants of hematite particles in aqueous suspensions: acomparison of two different surface morphologies, J. Colloid Interface Sci. 196 (1997) 241-253.

[21] R. Kretzschmar, H. Holthoff, H. Sticher, Influence of $\mathrm{pH}$ and humic acid on coagulation kinetics of kaolinite: a dynamic light scattering study, J. Colloid Interface Sci. 202 (1998) 95103.

[22] J. Lyklema, L. Deschênes, The first step in layer-by-layer deposition: Electrostatics and/or non-electrostatics?, Adv. in Colloid Interface Sci. 168 (2011) 135-148. 
This is a PDF file of an unedited manuscript that has been accepted for publication. Final edited form is published in Colloids and Surfaces A, 2013, 435:91-96. http://dx.doi.org/10.1016/j.colsurfa.2013.01.023

[23] P.Z. Araujo, P.J. Morando, M.A. Blesa, Interaction of Catechol and Gallic Acid with Titanium Dioxide in Aqueous Suspensions. 1. Equilibrium Studies, Langmuir 21 (2005) 3470-3474.

[24] E. Giannakopoulos, M. Drosos, Y. Deligiannakis, A humic-acid-like polycondensate produced with no use of catalyst, J. Colloid Interface Sci. 336 (2009) 59-66.

[25] M. Borkovec, G. Papastavrou, Interactions between solid surfaces with adsorbed polyelectrolytes of opposite charge, Curr. Opin. Colloid Interface Sci. 13 (2008) 429-437. [26] J.-D. Hu, Y. Zevi, X.-M. Kou, J. Xiao, X.-J. Wang, Y. Jin, Effect of dissolved organic matter on the stability of magnetite nanoparticles under different $\mathrm{pH}$ and ionic strength conditions, Sci. Total Environ. 408 (2010) 3477-3489. 